\title{
One gene determines maize B chromosome accumulation by preferential fertilisation; another gene(s) determines their meiotic loss
}

\author{
M González-Sánchez, E González-González, F Molina, AM Chiavarino, M Rosato and MJ Puertas \\ Departamento de Genética, Facultad de Biología, Universidad Complutense, 28040 Madrid, Spain
}

\begin{abstract}
Genotypes of high $\left(\mathrm{H}^{\mathrm{m}}\right)$ and low $\left(\mathrm{L}^{\mathrm{m}}\right)$ male $B$ transmission rate $(B-T R)$ were obtained. $B-T R$ segregation in the $F 2$ is reported, showing that the $\mathrm{H}^{\mathrm{m}}$ and $\mathrm{L}^{\mathrm{m}}$ lines differ in a single locus we call $m B t$ (male $B$ transmission), controlling $\mathrm{B}$ preferential fertilisation in maize. The egg cells control which one of the sperm nuclei is going to fertilise them, $m B t^{h}$ egg cells being preferentially fertilised by the sperm nucleus carrying the supernumerary B chromosomes (Bs). It is hypothesised that the $m B t$ gene is involved in the normal fertilisation of maize but the parasitic Bs take advantage of the $m B t^{h}$ allele to increase their own transmission. Selection was also carried out when the Bs were transmitted on the
\end{abstract}

female side $\left(\mathrm{H}^{f}\right.$ and $\mathrm{L}^{f}$ lines). The $\mathrm{F} 1$ hybrids show that the gene(s) that we call $f B t$ (female $B$ transmission), controlling female B-TR, is located on the A chromosomes acting at diploid level, the $\mathrm{fBt}^{\prime}$ allele(s) for low transmission being dominant. This allele causes the loss of Bs at meiosis, which is shown using a specific $B$ molecular probe to determine $B$ presence/absence in microspores of both lines and hybrids. Maize Bs are a nice example of intragenome conflict, because the $\mathrm{mBt}$ and $\mathrm{fBt}$ loci are a polymorphic system of attack and defence between $A$ and $B$ chromosomes.

Heredity (2003) 90, 122-129. doi:10.1038/sj.hdy.6800185

Keywords: B chromosomes; coevolution of genome conflict; Zea mays

\section{Introduction}

Supernumerary B chromosomes (Bs) are an interesting component of many eukaryotic genomes. In most species, Bs are 'selfish' or parasitic because they lack genes with specific phenotypic function, they have nonMendelian mechanisms of accumulation and their presence is deleterious to carriers when they are present at high numbers. Owing to these special features, Bs follow species-specific evolutionary pathways, which are poorly understood in most cases.

B chromosomes are widely distributed in maize, where numerical polymorphisms are frequently found. These polymorphisms are mediated by three main cytological processes: (i) B nondisjunction at the second pollen grain mitosis, which produces sperm nuclei with different B number (Roman, 1947; Carlson, 1978; Carlson and Chou, 1981); (ii) preferential fertilisation by the sperm nucleus carrying the Bs after the non-disjunction process (Roman, 1948; Carlson, 1969); (iii) the suppression of meiotic loss when the Bs are unpaired (Carlson and Roseman, 1992).

The genetic control of the nondisjunction process is owing to a region in the B chromosome itself, which was determined using deletions of B chromatin in B-A translocation lines (Lin, 1978, 1979; Carlson, 1978; Carlson and Chou, 1981). Variation in nondisjunction frequency was reported by Rusche et al (1997) using a

Correspondence: MJ Puertas, Departamento de Genética, Facultad de Biología, Universidad Complutense, 28040 Madrid, Spain.

E-mail:majetas@bio.ucm.es

Received 7 May 2002; accepted 19 August 2002 molecular probe to detect the presence, location and frequency of $\mathrm{B}$ chromosomes in interphase nuclei of pollen grains in the TB-10 L18 translocation line. However, when Bs are in their native form, the progeny of female $\mathrm{OB} \times$ male $2 \mathrm{~B}$ crosses has $\mathrm{OB}$ or $2 \mathrm{Bs}$ in more than $99 \%$ of the cases, demonstrating that non-disjunction occurs nearly always (Rosato et al, 1996; Chiavarino et al, 2001).

The genetic control of preferential fertilisation, when the Bs are transmitted on the male side, has been determined by selection of genotypes of high $\left(\mathrm{H}^{\mathrm{m}}\right)$ and low $\left(\mathrm{L}^{\mathrm{m}}\right) \mathrm{B}$ transmission rate (B-TR). In the former, B-TR is about 0.7, whereas in the latter it is about Mendelian (0.5) (Rosato et al, 1996). It was demonstrated that the gene/genes controlling B-TR on the male side are located on the normal A chromosome complement, because in female $0 \mathrm{~B} \times$ male $2 \mathrm{~B}$ crosses, the $\mathrm{B}$-TR depends on the $\mathrm{H}^{\mathrm{m}}$ or $\mathrm{L}^{\mathrm{m}}$ status of the $0 \mathrm{~B}$ parent (Chiavarino et al, 1998). It was concluded that the female parent controls B-TR on the male side, because when the $0 \mathrm{~B}$ female parent is $\mathrm{H}^{\mathrm{m}}$, it is preferentially fertilised by the sperm nucleus carrying 2Bs. On the contrary, when the $0 \mathrm{~B}$ female parent is $\mathrm{L}^{\mathrm{m}}$, it is fertilised by the $0 \mathrm{~B}$ or $2 \mathrm{~B}$ sperm nuclei at random.

The F1 hybrids between the $\mathrm{H}^{\mathrm{m}}$ and $\mathrm{L}^{\mathrm{m}}$ lines are uniform, showing intermediate B-TR and a low variance. These data, together with the fact that nearly all selection gain was obtained in the first generation of selection, allowed us to hypothesise that a single major gene is involved in the control of preferential fertilisation in maize (Chiavarino et al, 2001).

The present work reports the results of B-TR in the F2 generation, obtained by self-pollination of the F1, and 
shows unambiguously that the $\mathrm{H}^{\mathrm{m}}$ and $\mathrm{L}^{\mathrm{m}}$ lines differ in a single major gene.

Selection for high and low B-TR lines was also carried out when the Bs were transmitted on the female side $\left(\mathrm{H}^{\mathrm{f}}\right.$ and $\mathrm{L}^{\mathrm{f}}$ lines, respectively) in crosses female $1 \mathrm{~B} \times$ male $0 \mathrm{~B}$ (Rosato et al, 1996). It was found that the $\mathrm{H}^{\mathrm{f}}$ line has a Mendelian B-TR, whereas it is lower than Mendelian (about 0.4) in the $\mathrm{L}^{\mathrm{f}}$ line. It was also confirmed that nondisjunction does not occur on the female side because, in these $1 \mathrm{~B} \times 0 \mathrm{~B}$ crosses, the progeny has either $0 \mathrm{~B}$ or $1 \mathrm{~B}$ in more than $99 \%$ of the cases.

We also report on the B-TR obtained in the F1 hybrids between the $\mathrm{H}^{\mathrm{f}}$ and $\mathrm{L}^{\mathrm{f}}$ lines. We found that the gene/ genes controlling B-TR on the female side is located on the A chromosomes, acting at diploid level, the lowtransmission trait being dominant. We used a B-specific molecular probe to demonstrate that in $1 \mathrm{~B}$ plants of the $\mathrm{H}^{\mathrm{f}}$ line the $\mathrm{B}$ was present in $50 \%$ of the microspores. On the contrary, the $\mathrm{B}$ was present in a significantly lower number of microspores in plants of the $\mathrm{L}^{\mathrm{f}}$ line and in the F1 hybrids.

\section{Material and methods}

The materials used were selected lines of maize, Zea mays ssp. mays. On the one hand, we have used the lines selected for high and low $B$ transmission rate on the male side, where the crosses made during this selection process were female $0 \mathrm{~B} \times$ male $2 \mathrm{~B}$. As the $\mathrm{Bs}$ were always transmitted on the male side, we call these lines $\mathrm{H}^{\mathrm{m}}$ and $\mathrm{L}^{\mathrm{m}}$. The selection process was carried out following the method described in Rosato et al (1996) and Chiavarino et al (1998, 2001), which consists in selecting plants with the highest and nearly the lowest B$\mathrm{TR}$ in $\mathrm{OB} \times 2 \mathrm{~B}$ crosses. Plants with the lowest B-TR cannot be selected because their progenies do not contain sufficient Bs to continue the selection process.

On the other hand, we have used the lines selected for high and low B-TR on the female side, where the crosses made during the whole selection process were female $1 \mathrm{~B} \times$ male $0 \mathrm{~B}$. As the Bs were always transmitted on the female side we call these lines $\mathrm{H}^{\mathrm{f}}$ and $\mathrm{L}^{\mathrm{f}}$. The selection method is described in Rosato et al (1996).

The original material, from which the selection was initiated, belongs to the native race Pisingallo from NW Argentina (Rosato et al, 1998).

In all crosses mentioned in the present paper, the female parent will be indicated first; for example, a $0 \mathrm{~B} \times 2 \mathrm{~B}$ cross means that the female parent had $\mathrm{OB}$ and the male parent had 2Bs. Similarly, an HL hybrid is that obtained using a plant of the $\mathrm{H}$ line as female and a plant of the $\mathrm{L}$ line as male.

\section{Crosses for studying male $\mathrm{B}$ transmission rate}

The $\mathrm{H}^{\mathrm{m}} \mathrm{L}^{\mathrm{m}}$ and $\mathrm{L}^{\mathrm{m}} \mathrm{H}^{\mathrm{m}} \mathrm{F} 1$ hybrids were obtained. Thereafter, one $\mathrm{H}^{\mathrm{m}} \mathrm{L}^{\mathrm{m}} \mathrm{F} 1$ plant with $2 \mathrm{Bs}$ was self-pollinated to obtain the F2 segregation of the gene/genes involved. As the $\mathrm{H}^{\mathrm{m}} \mathrm{L}^{\mathrm{m}}$ and $\mathrm{L}^{\mathrm{m}} \mathrm{H}^{\mathrm{m}} \mathrm{F} 1$ hybrids have the same genetic composition and B-TR (Chiavarino et al, 2001), it is sufficient to study the F2 of either one of the hybrids. In this case, the $\mathrm{H}^{\mathrm{m}} \mathrm{L}^{\mathrm{m}} \mathrm{F} 2$ was used.

It has to be noted that to quantify B-TR, it is necessary to study the progeny of the plants involved. For that purpose, 120 F2 seeds were firstly scored for B number and then sown in an experimental field. As the F2 was obtained by self-pollination of one F1 2B plant, the number of $\mathrm{Bs}$ in the $\mathrm{F} 2$ plants corresponds to that produced in a $2 \mathrm{~B} \times 2 \mathrm{~B}$ cross. The $\mathrm{B}$ distribution in the progeny of $2 \mathrm{~B} \times 2 \mathrm{~B}$ crosses includes $0-5 \mathrm{~B}$ plants (Chiavarino et al, 2001). It should be mentioned that the progeny of $2 \mathrm{~B} \times 2 \mathrm{~B}$ crosses is expected to have 1 or $3 \mathrm{Bs}$, because the sperm nuclei carry 0 or $2 \mathrm{Bs}$ as a result of nondisjunction, whereas the female gametes should have $1 \mathrm{~B}$ if the Bs had a regular behaviour during megasporogenesis and megagametogenesis. However, 0, 2, 4 and rarely $5 \mathrm{~B}$ plants are also produced.

For studying male B-TR in the F2, it is necessary to use the F2 plants as females, because the genotype of the egg cell $\left(\mathrm{H}^{\mathrm{m}}\right.$ or $\left.\mathrm{L}^{\mathrm{m}}\right)$ determines the rate at which the egg cell is fertilised by the sperm nucleus with or without Bs (Chiavarino et al, 1998).

The 120 F2 seeds were used as female parents and were sown, all on the same day, in alternate rows with $2 \mathrm{~B}$ plants of the $\mathrm{H}^{\mathrm{m}}$ line that were used as male parents. The position of all plants in the experimental field was randomised and male parents were sown every 15 days to ensure that sufficient pollen would be available anytime. A few days before anthesis, the F2 female parents were emasculated and open-pollinated by the $2 \mathrm{~B}$ male parents. In this way, $61 \mathrm{~F} 2 \times 2 \mathrm{~B} \mathrm{H}^{\mathrm{m}}$ spikes with a large number of seeds were obtained to determine the $B$ transmission rate in the $\mathrm{F} 2$.

\section{Crosses for studying female $\mathrm{B}$ transmission rate}

$1 \mathrm{~B}$ and $\mathrm{OB}$ plants of the second generation of selection for high female B-TR were used to make $1 \mathrm{~B} \mathrm{H}^{\mathrm{f}} \times 0 \mathrm{~B} \mathrm{H}^{\mathrm{f}}$ crosses. The plants with the highest female B-TR were selected, corresponding to the third generation of the $\mathrm{H}^{\mathrm{f}}$ line. Also $1 \mathrm{~B}$ and $\mathrm{OB}$ plants of the second generation of selection for low B-TR were used to make $1 B \mathrm{~L}^{\mathrm{f}} \times 0 \mathrm{~B} \mathrm{~L}^{\mathrm{f}}$ crosses, corresponding to the third generation of selection of the $\mathrm{L}^{\mathrm{f}}$ line. $\mathrm{H}^{\mathrm{f}} \mathrm{L}^{\mathrm{f}}$ hybrids were obtained crossing $1 \mathrm{~B}$ $\mathrm{H}^{\mathrm{f}} \times 0 \mathrm{~B} \mathrm{~L}^{\mathrm{f}}$ plants and similarly, $1 \mathrm{~B} \mathrm{~L}^{\mathrm{f}} \times 0 \mathrm{~B} \mathrm{H^{ \textrm {f } }}$ plants were crossed to obtain the $\mathrm{L}^{\mathrm{f}} \mathrm{H}^{\mathrm{f}}$ hybrids.

\section{Cytological methods}

In all crosses described in the present work, at least 25-30 seeds per spike were scored to obtain B-TR. To score for B number, the primary root tips were pretreated with $0.002 \mathrm{~mol} / 1$ 8-hydroxyquinoline for $3 \mathrm{~h}$ at $20-22^{\circ} \mathrm{C}$, subsequently fixed in ethanol: acetic acid (3:1) and stained by the Feulgen method.

For fluorescence in situ hybridisation, anthers were fixed in ethanol: acetic acid (3:1) and squashed in $45 \%$ acetic acid. Squashed preparations were incubated with RNase A $\left(1 \mu \mathrm{g} / \mathrm{ml}\right.$, Sigma) in $2 \times \mathrm{SSC}$ for $1 \mathrm{~h}$ at $37^{\circ} \mathrm{C}$. Subsequently, the slides were rinsed three times for $5 \mathrm{~min}$ in $2 \times \mathrm{SSC}$, incubated in pepsin $0.1 \%$ for $5 \mathrm{~min}$ at $37^{\circ} \mathrm{C}$, fixed in $4 \%$ paraformaldehyde (Sigma) in $2 \times$ SSC for $10 \mathrm{~min}$ at room temperature, washed in $2 \times \mathrm{SSC}$ and then dehydrated in an ethanol series of 70, 95 and 100\%, 3 min each and air dried. Prior to hybridisation, the chromosome preparations were denatured in $70 \%(\mathrm{v} / \mathrm{v})$ formamide in $2 \times$ SSC at $62^{\circ}$ for $1 \mathrm{~min}$, dehydrated through an ice-cold ethanol series and air dried.

The hybridisation mixture contained $2 \mathrm{ng} / \mu \mathrm{l}$ of the maize B chromosome specific probe (Alfenito and Birchler, 1993), 50\% formamide and $10 \%$ dextran sulphate in $2 \times$ SSC. The DNA probe was labelled using nick translation with biotin-16-dUTP (Boehringer 
Mannheim). This mixture was denatured by boiling for $10 \mathrm{~min}$, quenched on ice for $7 \mathrm{~min}$ and added to the denatured slides. Hybridisation was performed overnight at $37^{\circ}$. Upon hybridisation, the slides were washed in $2 \times$ SSC at room temperature and then in $1 \times$ SSC at $37^{\circ}$ for $30 \mathrm{~min}$. The biotin-labelled probe was detected with avidin-conjugated Cy3 (Sigma) as primary antibody. Slides were counterstained with DAPI and mounted in anti-fade.

Slides were examined using an Olympus BX60 fluorescence microscope, photographed on 400 ISO colour negative film and the negatives scanned at $1350 \mathrm{dpi}$. The images were optimised for best contrast and brightness by means of Adobe Photoshop 6.0 image processing.

\section{Results}

\section{Male $\mathrm{B}$ transmission rate}

The $\mathrm{F} 2$ between the $\mathrm{H}^{\mathrm{m}}$ and $\mathrm{L}^{\mathrm{m}}$ lines was obtained to study the segregation of the gene/genes involved in male B-TR control. To estimate B-TR in the F2, these plants were crossed with $2 \mathrm{~B}$ plants as males. As the F2 plants may have $0-4$, or rarely 5 Bs and the $2 \mathrm{~B}$ males always produce $0 \mathrm{~B}$ and $2 \mathrm{~B}$ sperm nuclei, $0-4 \mathrm{~B}$ progeny is mainly expected. However, higher $B$ numbers can be found because infrequent instabilities of B chromosomes during gametogenesis.

Table 1 shows the progeny and the B-TR obtained in the 61 F2 plants studied. The table is distributed according to the number of Bs in the F2.

$\mathrm{B}-\mathrm{TR}$ of each class was estimated as follows. In the $\mathrm{OB}$ F2 female plants, only $0 B$ gametes can be formed, and therefore only $\mathrm{OB}$ and $2 \mathrm{~B}$ progeny is expected (Table 2). Thus, male B-TR was calculated dividing the number of $2 \mathrm{~B}$ plants in the progeny by the total number of plants scored. The 1B and 4B unexpected plants (Table 1) were discarded.

In the $1 \mathrm{~B} F 2$ female plants, both $\mathrm{OB}$ and $1 \mathrm{~B}$ gametes are formed and $0-3 B$ progeny can be obtained (Table 2); therefore, male B-TR was calculated dividing the number of $2 \mathrm{~B}$ and $3 \mathrm{~B}$ plants by the plant total. In this case, also the female B-TR can be unambiguously calculated as the number of $1 \mathrm{~B}+3 \mathrm{~B}$ progeny divided by the plant total (Table 2). Thus, the mean female B-TR was $0.382 \pm 0.024$. The correlation between the male and female B-TR in the $231 \mathrm{~B}$ plants was nonsignificant $(r=0.377, P=0.08)$.

In the $2 \mathrm{~B}$ F2 female plants only $1 \mathrm{~B}$ female gametes, and therefore only $1 \mathrm{~B}$ and $3 \mathrm{~B}$ progeny are expected; however, unexpected 0,2 and $4 \mathrm{~B}$ plants were obtained (Table 1).
Therefore, it is not possible to determine if the two Bs of the $2 \mathrm{~B}$ progeny come from the male or the female gametes (Table 2). To avoid this problem partially, we estimated male B-TR using only the expected progeny, so that it was calculated dividing the number of $3 \mathrm{~B}$ progeny by $1 \mathrm{~B}+3 \mathrm{~B}$ plants.

A similar problem occurs with the 3B F2 female plants, where $1 \mathrm{~B}$ and $2 \mathrm{~B}$ female gametes and therefore $1-4 \mathrm{~B}$ progeny are expected (Table 2), but 0,5 and $6 \mathrm{~B}$ unexpected plants were observed (Table 1). In this case, we estimated male $\mathrm{B}-\mathrm{TR}$ as the quotient $(3 \mathrm{~B}+4 \mathrm{~B}) /$ $(1 \mathrm{~B}+2 \mathrm{~B}+3 \mathrm{~B}+4 \mathrm{~B})$.

In $4 \mathrm{~B}$ F2 progeny only $2 \mathrm{~B}$ and $4 \mathrm{~B}$ progeny was expected, but $1-6 \mathrm{~B}$ plants were found. We did not consider this class because it is not possible to calculate B-TR with sufficient accuracy (Table 2).

The main interest of this F2 segregation is to calculate the variance of the character, which allows the estimation of the number of loci involved using Wright's equation (Wright, 1968) $N=\left(x_{\mathrm{L}}-x_{\mathrm{H}}\right)^{2} / 8\left(V_{\mathrm{F} 2}-V_{\mathrm{F} 1}\right)=1.06$, demonstrating that a single gene is controlling male B-TR. The values of $x_{\mathrm{L}}, x_{\mathrm{H}}, V_{\mathrm{F} 1}$ and $V_{\mathrm{F} 2}$ are shown in Table $3 ; x_{\mathrm{L}}, x_{\mathrm{H}}$ and $V_{\mathrm{F} 1}$ were reported in Chiavarino et al (2001).

\section{Female $\mathrm{B}$ transmission rate}

In this case, crosses were made to compare B-TR in the $\mathrm{H}^{\mathrm{f}}$ and $\mathrm{L}^{\mathrm{f}}$ lines with the $\mathrm{H}^{\mathrm{f}} \mathrm{L}^{\mathrm{f}}$ and $\mathrm{L}^{\mathrm{f}} \mathrm{H}^{\mathrm{f}}$ hybrids. In all cases, the crosses were either $1 \mathrm{~B} \times 0 \mathrm{~B}$ or $1 \mathrm{~B} \times 1 \mathrm{~B}$. As nondisjunction does not occur on the female side, female BTR is calculated dividing the number of individuals of the progeny with odd number of Bs by the plant total. BTR values are shown in Table 4 .

One-way ANOVA was made to compare B-TR as the dependent variable and the genotype as the independent variable. The ANOVA showed that the four groups significantly differ $\left(F_{3,35}=6.76 ; P=0.001\right)$. On the other hand, Scheffé post hoc test showed that B-TR is significantly different in the $\mathrm{H}^{\mathrm{f}}$ line, but there were no significant differences among the other three groups.

As shown in Table 4, B-TR in the $\mathrm{H}^{\mathrm{f}}$ line is about Mendelian (0.5), whereas in the $\mathrm{L}^{\mathrm{f}}$ line and both hybrids $\mathrm{B}-\mathrm{TR}$ is lower than Mendelian, indicating that a fraction of the Bs has been lost during female meiosis and/or megagametogenesis. Unfortunately, it is not possible to quantify the $B$ behaviour at female meiosis and gametogenesis; but we studied male meiosis in the four genotypes to see if B loss occurred also on the male side.

In situ hybridisation was made in microspores of $1 \mathrm{~B}$ plants, with the pZmBs probe, specific to $\mathrm{B}$ chromo-

Table $1 \mathrm{~B}$ transmission in the $\mathrm{F} 2$ between the $\mathrm{H}^{\mathrm{m}}$ and $\mathrm{L}^{\mathrm{m}}$ lines

\begin{tabular}{|c|c|c|c|c|c|c|c|c|c|c|}
\hline \multirow{2}{*}{$\begin{array}{l}\text { Bs in the } \\
\text { F2 plant }\end{array}$} & \multirow{2}{*}{$\begin{array}{l}\text { Number } \\
\text { of plants }\end{array}$} & \multicolumn{7}{|c|}{ Bs in the progeny } & \multirow{2}{*}{$\begin{array}{l}\text { Total no. } \\
\text { ind. scored }\end{array}$} & \multirow{2}{*}{$\begin{array}{c}\text { Mean } \\
\text { B-transmission } \\
\text { rate } \pm S E\end{array}$} \\
\hline & & 0 & 1 & 2 & 3 & 4 & 5 & 6 & & \\
\hline 0 & 6 & 70 & 1 & 81 & & 1 & & & 153 & $0.535 \pm 0.028$ \\
\hline 1 & 23 & 160 & 105 & 194 & 117 & 1 & & & 577 & $0.538 \pm 0.023$ \\
\hline 2 & 11 & 16 & 112 & 49 & 122 & 20 & & & 319 & $0.523 \pm 0.041$ \\
\hline 3 & 19 & 10 & 127 & 108 & 138 & 87 & 5 & 2 & 477 & $0.491 \pm 0.027$ \\
\hline 4 & 2 & & 6 & 10 & 19 & 19 & 14 & 1 & 69 & Not considered \\
\hline Total & 61 & 256 & 351 & 442 & 396 & 128 & 19 & 3 & 1595 & $0.520 \pm 0.016$ \\
\hline
\end{tabular}


Table 2 Possible progeny in $\mathrm{F} 2 \times 2 \mathrm{~B} \mathrm{H}$ crosses
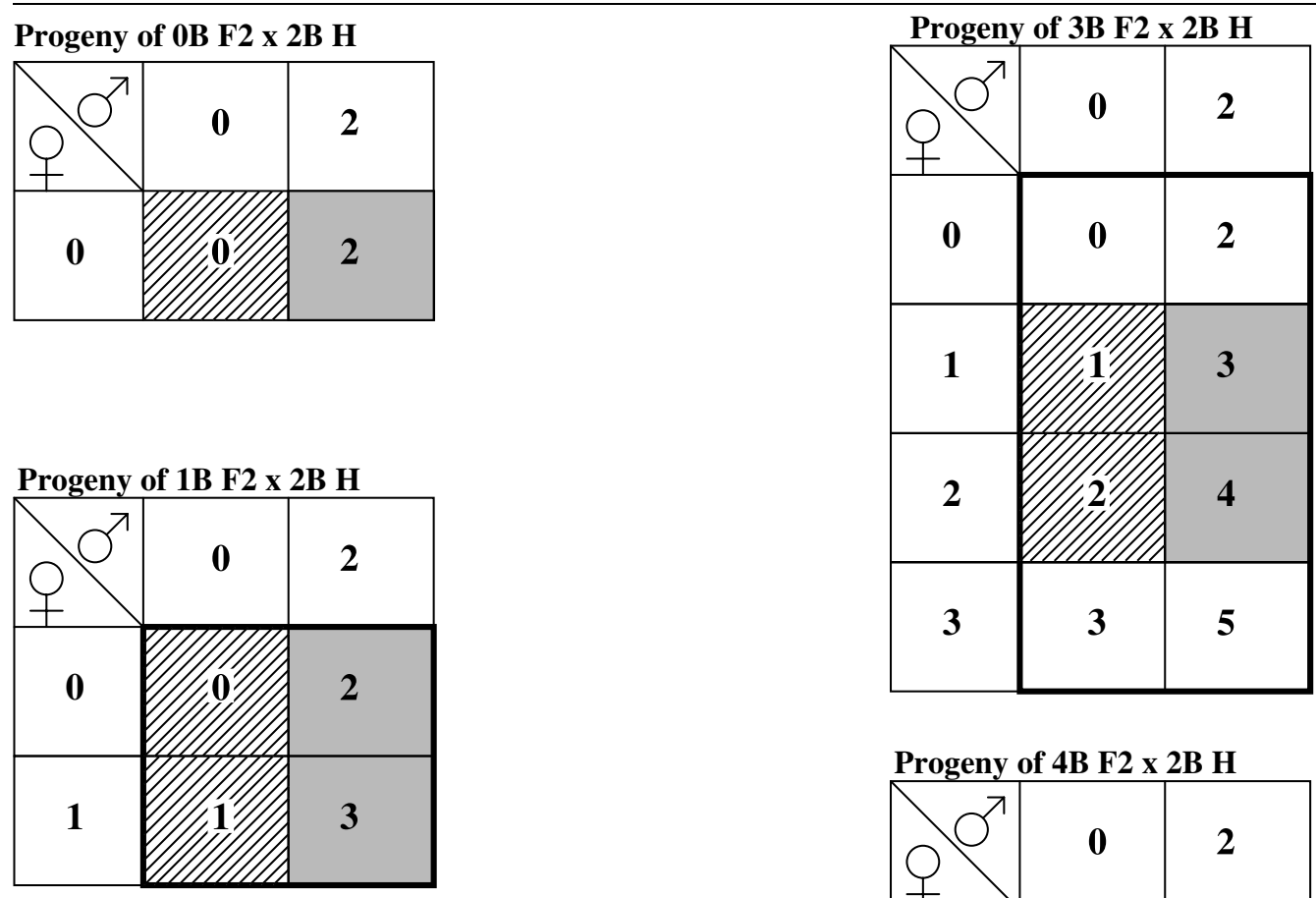

\begin{tabular}{|c|c|c|}
\hline \multicolumn{3}{|c|}{ Progeny of 4B F2 x 2B H } \\
\hline 0 & 0 & 2 \\
\hline 1 & 1 & 3 \\
\hline 2 & 2 & 4 \\
\hline 3 & 3 & 5 \\
\hline 4 & 4 & 6 \\
\hline
\end{tabular}

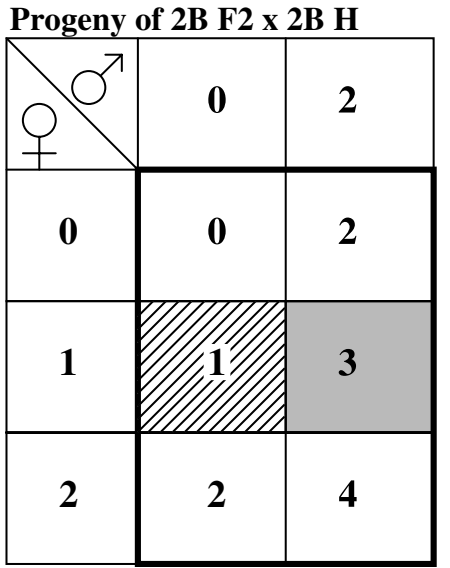

\section{considered to estimate $\mathrm{B}$ transmission rate.}

Shaded: progeny where Bs were not transmitted on the male side. Grey: progeny where Bs were transmitted on the male side. Unlabelled: not

Table 3 Male B transmission rate in the $\mathrm{H}^{\mathrm{m}}$ and $\mathrm{L}^{\mathrm{m}}$, parental lines, F1 and F2

\begin{tabular}{lccc}
\hline Type of cross & No. of crosses & Mean B-TR & Variance \\
\hline $\mathrm{H}^{\mathrm{m}} \times \mathrm{H}^{\mathrm{m}}$ & 17 & 0.750 & 0.0082 \\
$\mathrm{~L}^{\mathrm{m}} \times \mathrm{L}^{\mathrm{m}}$ & 14 & 0.467 & 0.0095 \\
$\mathrm{~F} 1 \times \mathrm{F} 1$ & 18 & 0.583 & 0.0033 \\
$\mathrm{~F} 2 \times 2 \mathrm{~B} \mathrm{H} \mathrm{H}^{\mathrm{m}}$ & 59 & 0.520 & 0.0127 \\
\hline
\end{tabular}

somes, to score for the number of microspores with or without the B (Figure 1). In a few cases, microspores were found together with a labelled micronucleus. The two last columns of Table 4 show the number of scored microspores and the mean of microspores showing the $\mathrm{B}$ label.

One-way ANOVA showed significant differences in the frequency of B-carrying microspores among the four genotype classes $\left(F_{3,21}=8.88 ; P=0.001\right)$. Scheffé post hoc test showed that the $\mathrm{H}^{\mathrm{f}}$ line showed significantly higher frequencies of microspores that the three other groups, which did not differ among them.

\section{Discussion}

The present work continues, and to some extent culminates, the selection experiments designed to determine the genetic control of $\mathrm{B}$ chromosome transmission 
Table 4 B transmission rate and B conservation in microspores of the $\mathrm{H}^{\mathrm{f}}$ and $\mathrm{L}^{\mathrm{f}}$ lines, and in the $\mathrm{H}^{\mathrm{f}} \mathrm{L}^{\mathrm{f}}$ and $\mathrm{L}^{\mathrm{f}} \mathrm{H}^{\mathrm{f}} \mathrm{F} 1$ hybrids

\begin{tabular}{|c|c|c|c|c|c|}
\hline $\begin{array}{l}\text { Type of } \\
\text { cross }\end{array}$ & $\begin{array}{l}\text { No. of } \\
\text { crosses }\end{array}$ & $\begin{array}{l}\text { Total no. ind. } \\
\text { scored }\end{array}$ & $\begin{array}{l}\text { Mean B-TR } \\
\quad \pm S E\end{array}$ & $\begin{array}{l}\text { No. of scored } \\
\text { microspores }\end{array}$ & $\begin{array}{l}\text { Microspores } \\
\text { with the B }\end{array}$ \\
\hline $\mathrm{H}^{\mathrm{f}} \times \mathrm{H}^{\mathrm{f}}$ & 10 & 250 & $0.510 \pm 0.019$ & 826 & $0.502 \pm 0.011$ \\
\hline$L^{f} \times L^{f}$ & 9 & 235 & $0.381 \pm 0.022$ & 998 & $0.428 \pm 0.018$ \\
\hline $\mathrm{H}^{\mathrm{f}} \mathrm{L}^{\mathrm{f}} \times \mathrm{H}^{\mathrm{f}} \mathrm{L}^{\mathrm{f}}$ & 10 & 257 & $0.389+0.032$ & 1241 & $0.421+0.012$ \\
\hline $\mathrm{L}^{f} \mathrm{H}^{\mathrm{f}} \times \mathrm{L}^{\mathrm{f}} \mathrm{H}^{\mathrm{f}}$ & 7 & 174 & $0.352 \pm 0.043$ & 1171 & $0.418 \pm 0.020$ \\
\hline
\end{tabular}
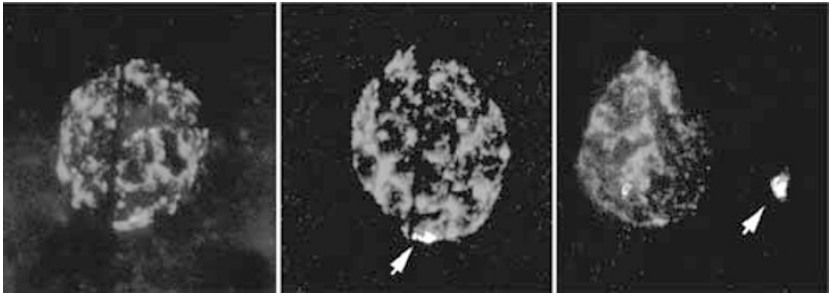

Figure 1 In situ hybridisation in microspores of $1 \mathrm{~B}$ plants of the $\mathrm{L}^{\mathrm{f}}$ line, using the $\mathrm{pZmBs}$ probe, specific to $\mathrm{B}$ chromosomes. (a) microspore without the $\mathrm{B}$; (b) microspore with the $\mathrm{B}$ (arrow); (c) microspore without the $\mathrm{B}$, which is lost as micronucleus (arrow).

in maize (Rosato et al, 1996; Chiavarino et al, 1997, 1998, 2001; Puertas et al, 2000). This is important to determine the forces maintaining $B$ polymorphism in natural populations and, furthermore, to understand the significance of this parasitic part of the genome.

\section{$\mathrm{B}$ transmission and male B-TR estimation}

The transmission of $2 \mathrm{Bs}$ on the male side is regularly nondisjunctional. In the cross $\mathrm{F} 2 \mathrm{OB} \times 2 \mathrm{BH}^{\mathrm{m}}$, most of the offspring had $\mathrm{OB}$ or $2 \mathrm{~B}$ as a consequence of nondisjunction. Only one plant $(0.65 \%)$ had $1 B$, indicating lack of nondisjunction and one plant had $4 \mathrm{Bs}$ owing to other irregularities during male gametogenesis.

Also in the cross $\mathrm{F} 21 \mathrm{~B} \times 2 \mathrm{BH}^{\mathrm{m}}$, the regularity of $\mathrm{B}$ transmission on the male side is observed, as only one unexpected $4 \mathrm{~B}$ plant was found $(0.17 \%)$. In agreement with Randolph (1941), this cross also demonstrates that B nondisjunction does not occur on the female side; otherwise, many more $4 \mathrm{~B}$ plants would have been observed.

Variation in B nondisjunction frequency was reported by Lin $(1978,1979)$ and Rusche et al (1997) in the TB-10 L18 B-A translocation. However, our results consistently show that the native $B$ undergoes a repeatable behaviour at male gametogenesis, almost always producing $\mathrm{OB}$ and 2B sperm nuclei.

On the contrary, $2 \mathrm{~B}$ and $3 \mathrm{~B}$ transmission on the female side shows a remarkable frequency of irregularities. In the cross $\mathrm{F} 22 \mathrm{~B} \times 2 \mathrm{BH}^{\mathrm{m}}, \mathrm{OB}(5 \%)$ and $4 \mathrm{~B}(6.2 \%)$ progeny was observed. In the cross $\mathrm{F} 23 \mathrm{~B} \times 2 \mathrm{BH}^{\mathrm{m}}, \mathrm{OB}(2 \%), 5 \mathrm{~B}$ $(1 \%)$ and $6 \mathrm{~B}(0.4 \%)$ progeny was obtained. In both crosses, this progeny demonstrates that the Bs underwent irregularities at female meiosis at a much higher frequency than they did on the male side. The mentioned irregularities seem to indicate that Bs do not form always bivalents. If there is $\mathrm{B}$ univalency in some extent, $\mathrm{OB}$ or $4 \mathrm{~B}$ progeny might be formed in $2 \mathrm{~B} \times 2 \mathrm{~B}$ crosses. However, $6 \mathrm{~B}$ progeny is actually unexpected in a $3 \mathrm{~B} \times 2 \mathrm{~B}$ cross since it shows more Bs than the sum of Bs in the parents. Randolph (1941) likewise reported similar irregularities in $2 \mathrm{~B} \times 0 \mathrm{~B}$ and $3 \mathrm{~B} \times 0 \mathrm{~B}$ crosses.
Male B-TR was unambiguously estimated in F2 $0 \mathrm{~B} \times 2 \mathrm{BH}^{\mathrm{m}}$ and $\mathrm{F} 21 \mathrm{~B} \times 2 \mathrm{BH}^{\mathrm{m}}$ crosses because $\mathrm{B}$ transmission on the male side can be directly deduced from their progeny. Both estimates are nearly identical (Table 1) showing that B number on the female side does not affect male B-TR. This was already reported by Chiavarino et al (2001) comparing $0 \mathrm{~B} \times 2 \mathrm{~B}$ and $2 \mathrm{~B} \times 2 \mathrm{~B}$ crosses.

In the $\mathrm{F} 2 \mathrm{2} \times 2 \mathrm{BH}^{\mathrm{m}}$ cross, male $\mathrm{B}-\mathrm{TR}$ may be estimated using three criteria. (i) Minimum estimate, considering that all 2B plants in the progeny come from 2B female gametes and $0 \mathrm{~B}$ male gametes (Table 2 ). In this case male $\mathrm{B}-\mathrm{TR}=(3 \mathrm{~B}+4 \mathrm{~B}) /$ total $=0.445$. (ii) Maximum estimate, considering that all $2 \mathrm{~B}$ plants in the progeny come from $\mathrm{OB}$ female gametes and $2 \mathrm{~B}$ male gametes; then, male $\mathrm{B}-\mathrm{TR}=(2 \mathrm{~B}+3 \mathrm{~B}+4 \mathrm{~B}) /$ total $=0.598$. (iii) Intermediate estimate, considering only the progeny formed with the expected $1 \mathrm{~B}$ female gametes. In this case male B$\mathrm{TR}=3 \mathrm{~B} /(1 \mathrm{~B}+3 \mathrm{~B})=0.523$. We think that this calculation is the least ambiguous, and so it was used in the general estimation of F2 B-TR mean and variance.

In the $\mathrm{F} 23 \mathrm{~B} \times 2 \mathrm{BH}^{\mathrm{m}}$ cross, a small ambiguity in B-TR estimation is unavoidable. It is expected that $3 \mathrm{~B}$ plants form $1 \mathrm{~B}$ and $2 \mathrm{~B}$ female gametes, giving rise to $1-4 \mathrm{Bs}$ in the progeny (Table 2). However, $2 \mathrm{~B}$ progeny may appear if $2 \mathrm{~B}$ male gametes fertilised unexpected $\mathrm{OB}$ female gametes. Similarly, 3B progeny may appear if $0 \mathrm{~B}$ male gametes fertilised unexpected $3 \mathrm{~B}$ female gametes. $\mathrm{OB}$ and 3B female gametes may be formed if the 3 Bs segregate to the same pole at female meiosis. These gametes are really formed because $\mathrm{OB}$ and $5 \mathrm{~B}$ progeny are found in this cross. Randolph (1941) also reported OB and 3B progeny in $3 \mathrm{~B} \times 0 \mathrm{~B}$ crosses.

In spite of this ambiguity, we have estimated male $B-$ $T R=(3 B+4 B) /(1 B+2 B+3 B+4 B)$ because the error is very small. Firstly, because the number of $0 \mathrm{~B}$ and $5 \mathrm{~B}$ plants is small $(2.09 \%$ and $1.05 \%$, respectively) and secondly, because the excess of $3 \mathrm{~B}$ plants in the numerator is in all probability compensated by the excess of $2 \mathrm{~B}$ plants in the denominator.

\section{Number of loci controlling male B-TR}

Chiavarino et al (2001) hypothesised that a single major gene controls male B-TR in maize. In the present work the F2 between the $\mathrm{H}^{\mathrm{m}}$ and $\mathrm{L}^{\mathrm{m}}$ lines was obtained to test this hypothesis, to estimate the number of independently segregating pairs of alleles according to Wright (1968), which confirmed the hypothesis. This estimate is subject to limitations; firstly, many populations and their F1's should be considered for the specification of nongenetic variability. Unfortunately, such an experiment is unattainable in our case. Secondly, it is assumed that the segregating loci are independent and their effects are additive. In our case, as only one locus with intermediate effect in the F1 is obtained, this assumption is fully accomplished. 
Wright also considered the case when practically all of the F2 variance is a consequence of segregation of one pair of alleles with semidominance. He considers that a multiplicity of minor factors might contribute to the range between the parents, at opposite extremes, but their contributions to variance are negligible when combined in the F2.

Chiavarino et al $(1998,2001)$ demonstrated that the genetic control of male B-TR depends on preferential fertilisation and is located on the A chromosomes, acting in the egg cell at the haploid level. Egg cells of the $\mathrm{H}^{\mathrm{m}}$ line are preferentially fertilised by the sperm nucleus carrying 2Bs, whereas egg cells of the $\mathrm{L}^{\mathrm{m}}$ line are fertilised by both sperm nuclei at random resulting in a Mendelian B-TR. After our finding of only one gene that we call $m B t$, controlling $\mathrm{B}$ preferential fertilisation in maize, we can conclude that egg cells with the $m B t^{h}$ allele are preferentially fertilised by the sperm nucleus carrying 2Bs, whereas $m B t^{l}$ egg cells are randomly fertilised by the $0 \mathrm{~B}$ or $2 \mathrm{~B}$ sperm nucleus.

This $m B t$ gene is not only interesting for controlling male B-TR, but also because it shows that egg cells may control which one of the sperm nuclei is going to fertilise them. This ability was not demonstrated before, since pollen-style interactions were thought to be due only to sporophytic diploid tissues on the female side.

\section{Genetic control of female B-TR; a two-locus model}

The crosses $\mathrm{F} 2 \mathrm{~B} \times 2 \mathrm{BH}^{\mathrm{m}}$ allow us to estimate male and female B-TR in the same plants. As the correlation between them is non-significant, it is concluded that different genes control both processes.

Further knowledge of this control on the female side was obtained from the lines selected for high $\left(\mathrm{H}^{\mathrm{f}}\right)$ and low $\left(\mathrm{L}^{\mathrm{f}}\right) \mathrm{B}-\mathrm{TR}$ on the female side and their hybrids. In both hybrids B-TR is similar (Table 4). As in the $\mathrm{H}^{\mathrm{f}} \mathrm{L}^{\mathrm{f}}$ hybrids the $\mathrm{B}$ comes from the $\mathrm{H}^{\mathrm{f}}$ line and in the $\mathrm{L}^{\mathrm{f}} \mathrm{H}^{\mathrm{f}}$ hybrids the B comes from the $\mathrm{L}^{\mathrm{f}}$ line, B-TR is independent of which genotype the $1 \mathrm{~B}$ female progenitor possesses. Therefore, we conclude that the gene or genes controlling B-TR on the female side are located on the A chromosomes.

B-TR in the hybrids is similar to that observed in the $\mathrm{L}^{\mathrm{f}}$ line, but it is significantly different from that of the $\mathrm{H}^{\mathrm{f}}$ line. Therefore, it is concluded that this gene(s) acts at the diploid level, the $f B t^{l}$ allele(s) being dominant.

This conclusion is further supported by the results obtained studying the presence/absence of the $B$ in microspores of both lines and hybrids using the specific $\mathrm{B}$ molecular probe. It is evident that Bs were lost during male meiosis in the $\mathrm{L}^{\mathrm{f}}$ line, $\mathrm{H}^{\mathrm{f}} \mathrm{L}^{\mathrm{f}}$ and $\mathrm{L}^{\mathrm{f}} \mathrm{H}^{\mathrm{f}}$ hybrids, whereas meiotic loss did not occur in the $\mathrm{H}^{\mathrm{f}}$ line. Frequent chromosome instabilities during male gametogenesis in the tapetum in the $\mathrm{L}^{\mathrm{f}}$ line were reported in Chiavarino et al (2000).

Carlson and Roseman (1992) reported that one of the mechanisms of the maintenance of maize B chromosomes is the lack of meiotic loss when Bs are unpaired. They found that, in the $T B-9 S b \mathrm{~A} / \mathrm{B}$ translocation, suppression of meiotic loss is controlled by at least one proximal and one distal region on the B chromosome. Kaszás and Birchler (1998) used misdivision derivatives of the $B$ centromere in the same TB-9Sb reciprocal translocation to compare their molecular composition with meiotic transmission, reporting a strong correlation between the size of the $B$ centromere and meiotic transmission.

However, meiotic loss seems to have a more complicated control. Our results demonstrate that, in the native $\mathrm{B}$, meiotic loss is also controlled by the A chromosomes, the $f B t^{h}$ allele being responsible for the lack of meiotic loss, whereas the dominant $f B t^{l}$ allele produces $B$ loss at meiosis.

It should also be noted that in the $\mathrm{H}^{\mathrm{f}}$ line the $\mathrm{B}$ is never lost because B-TR is Mendelian (0.5) and equal to the mean of microspores with the B. However, in the $\mathrm{L}^{\mathrm{f}}$ line, $\mathrm{H}^{\mathrm{f}} \mathrm{L}^{\mathrm{f}}$ and $\mathrm{L}^{\mathrm{f}} \mathrm{H}^{\mathrm{f}}$ hybrids, the mean of microspores with the $\mathrm{B}$ is higher than B-TR (Table 4). We do not know the causes accounting for the difference. Higher B loss during female meiosis or megagametogenesis could be the cause, but a quantitative study of female meiosis in maize is unattainable.

Previous results show that B meiotic loss occurs when Bs are unpaired. Two Bs form bivalents and show normal segregation in both the $\mathrm{H}^{\mathrm{m}}$ and $\mathrm{L}^{\mathrm{m}}$ lines (Chiavarino et al, 1997). However, meiosis in $2 B$ plants of the $\mathrm{H}^{\mathrm{f}}$ and $\mathrm{L}^{\mathrm{f}}$ lines has not been studied.

From our results it is concluded that at least two loci control B-TR in maize: one, $m B t$ on the male side and one $f B t$ on the female side. The $m B t^{h}$ allele tends to increase BTR over Mendelian transmission, whereas the $f B t^{l}$ allele tends to decrease it.

Interestingly, a two-locus model was also proposed for the mealybug Pseudococcus affinis, which possesses a lecanoid genetic system. It was the first species for which the number of genes controlling B-TR was estimated (Nur and Brett, 1987). They assumed firstly that B-TR in males is determined only by alleles in the euchromatic set and thus the males are functionally haploid. Secondly, that each locus affecting B-TR has two alleles one for high and other for low B-TR. Under such assumptions, a two-locus model could account for their data.

\section{Coevolution between $A$ and $B$ chromosomes}

Maize Bs are a nice example of intragenome conflict (Frank, 2000), because the $m B t$ locus and $f B t$ locus/loci constitute a polymorphic system of attack and defence between $\mathrm{A}$ and $\mathrm{B}$ chromosomes. In maize, the Bs show accumulation mechanisms and infringe slightly deleterious phenotypic effects on the host plant. Therefore, they can be classified as moderately parasitic according to Camacho et al (2000). They have no effect on the phenotype at the normal number (0-3 per plant) found in native populations, although they produce deleterious effects when there are 5 or more Bs (Randolph, 1941; Kato, 1970; Staub, 1987). This means that Bs should be maintained at low numbers and, therefore, alleles in the A genome providing defence against the $B$ attack are expected to increase in frequency.

Our hypothesis is that the main function of the $m B t$ gene, controlling male B-TR, is not to determine B preferential fertilisation rate. We think that this gene, acting at haploid level in the egg-cell, is involved in the normal fertilisation process, but the Bs take advantage of the $m B t^{h}$ function to increase their own transmission, allowing $\mathrm{B}$ accumulation and hence $\mathrm{B}$ chromosome attack. The $m B t^{l}$ allele could be the response of the host A genome to get rid of the B effects, suppressing $\mathrm{B}$ accumulation and providing $\mathrm{A}$ chromosome defence. 


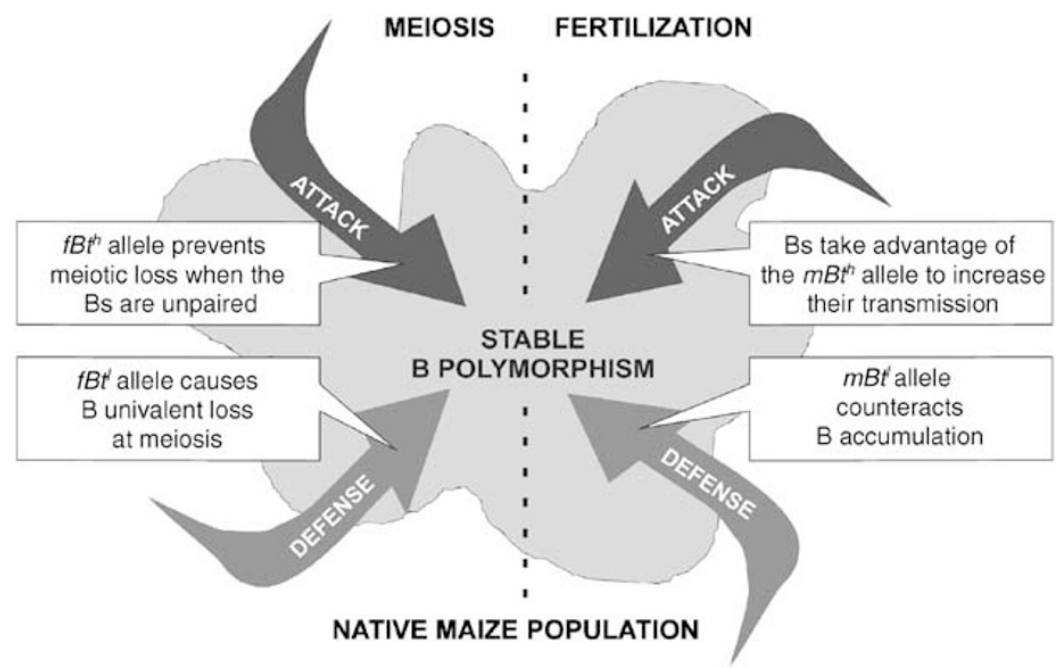

Figure 2 Model of coevolution of B attack and A defence in a native maize population. At meiosis B loss is prevented in homozygous $f B t^{h} f B t^{h}$ plants. The A defence is provided by the $f B t^{l}$ dominant allele. At fertilisation, B attack occurs in $m B t^{h}$ egg cells which are preferentially fertilised by B carrying male gametes. Egg cells with the $m B t^{l}$ allele tend to counteract $\mathrm{B}$ accumulation, because they are fertilised by $0 \mathrm{~B}$ or $2 \mathrm{~B}$ sperm nuclei at random.

Another system complements this function acting at diploid level during meiosis. The $f B t$ locus/loci acts in such a way that in the $f B t^{h} f B t^{h}$ homozygote the unpaired Bs are not lost, providing $B$ attack, whereas in all plants carrying the dominant $f B t^{l}$ allele the unpaired Bs tend to be lost, providing an efficient A chromosome defence. This model is represented in Figure 2.

The coevolution of As and Bs in maize is also in agreement with the non-equilibrium model proposed for the grasshopper Eyprepocnemis plorans where the Bs have been neutralised by the A genome (Camacho et al, 1997a, b; Zurita et al, 1998, reviewed in Camacho et al, 2000). The nonequilibrium model of long-term evolution of $\mathrm{B}$ chromosomes is considered to be the outcome of selection on the host genome to eliminate B chromosomes or suppress their effects, and on the B ability to escape through the generation of new variants. However, in our case we have no evidence for the generation of new B variants because our experiments were done in only one population. The estimation of allelic frequencies of the $m B t$ and $f B t$ loci in native populations with very high and very low $B$ frequency might provide insights to solve this problem.

\section{Acknowledgements}

This work was supported by grant 98-0678 of the Dirección General de Enseñanza Superior e Investigación Científica (Ministerio de Educación y Cultura) of Spain. AM Chiavarino and M Rosato were postdoctoral grant holders of the CONICET (Argentina).

\section{References}

Alfenito MR, Birchler JA (1993). Molecular characterization of a maize B chromosome centric sequence. Genetics 135: 589-597.

Camacho JM, Cabrero J, López-León MD, Shaw MW (1997a). Evolution of a near-neutral B chromosome. In: Henriques-Gil N, Parker JS, Puertas MJ (eds) Chromosomes Today, Chapman \& Hall: London, Vol. 12, pp 301-318.
Camacho JPM, Shaw MW, López-León MD, Pardo MC, Cabrero J (1997b). Population dynamics of a selfish B chromosome neutralized by the standard genome in the grasshopper Eyprepocnemis plorans. Am Nat 149: 1030-1150.

Camacho JPM, Sharbel TF, Beukeboom LW. (2000). B-chromosome evolution. Philos Trans R Soc Lond B 355: 163-178.

Carlson WR (1969). Factors affecting preferential fertilisation in maize. Genetics 62: 543-554.

Carlson WR (1978). The B chromosome of corn. Ann Rev Genet 16: 5-23.

Carlson WR, Chou TS (1981). B chromosome nondisjunction in corn: control factors near the centromere. Genetics 97: 379-389.

Carlson WR, Roseman R (1992). A new property of the maize B chromosome. Genetics 131: 211-223.

Chiavarino AM, Rosato M, Rosi P, Naranjo CA, Poggio L (1997). $\mathrm{B}$ chromosomes in native races of maize from Argentina. III. Selection of high and low transmission genotypes and meiotic behavior of Bs. Maize Genet Coop Newslett (USA) 71: $48-49$.

Chiavarino AM, Rosato M, Rosi P, Poggio L, Naranjo CA (1998). Localization of the genes controlling $\mathrm{B}$ chromosome transmission rate in maize (Zea mays ssp. mays, Poaceae). Am J Bot 85: 1581-1585.

Chiavarino AM, Rosato M, Manzanero S, Jiménez G, GonzálezSánchez M, Puertas MJ (2000). Chromosome nondisjunction and instabilities in tapetal cells are affected by B chromosomes in maize. Genetics 155: 889-897.

Chiavarino AM, González-Sánchez M, Poggio L, Puertas MJ, Rosato M, Rosi P (2001). Is maize B chromosome preferential fertilisation controlled by a single gene? Heredity 86: 743-748.

Frank SA (2000). Polymorphism of attack and defence. TREE 15: 167-171.

Kato TA (1970). Influence of B chromosomes on 4 characters. Maize Genet Coop Newslett 44: 18-21.

Kaszás E, Birchler JA (1998). Meiotic transmission rates correlates with physical features of rearranged centromeres in maize. Genetics 150: 1683-1692.

Lin BY (1978). Regional control of nondisjunction of the B chromosome in maize. Genetics 90: 613-627.

Lin BY (1979). Two new B-10 translocation involved in the control of nondisjunction of the B chromosome in maize. Genetics 92: 930-945.

Nur U, Brett BLH (1987). Control of meiotic drive of B chromosomes in the mealybug Pseudococcus affinis (obscurus.). Genetics 115: 499-510. 
Puertas MJ, Jiménez G, Manzanero S, Chiavarino AM, Rosato M, Naranjo CA, Poggio L (2000). Genetic control of B chromosome transmission in maize and rye. In: Olmo E, Redi CA (eds) Chromosomes Today. Birkhäuser Verlag: Switzerland. Vol. 13, pp 79-92.

Randolph LF (1941). Genetic characteristics of the B chromosomes in maize. Genetics 26: 608-631.

Roman H (1947). Mitotic nondisjunction in the case of interchanges involving the B-type chromosome in maize. Genetics 32: 391-409.

Roman H (1948). Directed fertilisation in maize. Proc Natl Acad Sci USA 34: 36-42.

Rosato M, Chiavarino AM, Naranjo CA, Puertas MJ, Poggio L (1996). Genetic control of B chromosome transmission rate in Zea mays ssp. mays (Poaceae). Am J Bot 83: 1107-1112.
Rosato M, Chiavarino AM, Naranjo CA, Cámara-Hernández J, Poggio L (1998). Genome size and numerical polymorphism for the B chromosome in races of maize (Zea mays ssp. mays, Poaceae). Am J Bot 85: 168-174.

Rusche ML, Mogensen HL, Shi L, Keim P, Rougier M, Chaboud A, Dumas C (1997). B chromosome behavior in maize pollen as determined by a molecular probe. Genetics 14: 1915-1921.

Staub RW (1987). Leaf striping correlated with the presence of B chromosomes in maize. J Hered 78: 71-74.

Wright S (1968). Evolution and the Genetics of Populations, Vol. 1. Genetic and Biometric Foundations. The University of Chicago Press: Chicago.

Zurita S, Cabrero J, López-León MD, Camacho JPM (1998). Polymorphism regeneration for a neutralized selfish B chromosome. Evolution 52: 274-277. 